\title{
Reflexões sobre os métodos de validações de jogos virtuais no ensino e aprendizagem da Matemática
}

\section{Considerations about validations methods of virtual games in teaching and learning of Mathematics}

\author{
Luana Henrichsen \\ Instituto Federal de Educação, Ciência e Tecnologia do Rio Grande do Sul (IFRS), Campus \\ Ibirubá, Ibirubá, RS, Brasil \\ https://orcid.org/0000-0003-0522-5666, luanabehnenh@gmail.com
}

\begin{abstract}
Rodrigo Farias Gama
Instituto Federal de Educação, Ciência e Tecnologia do Rio Grande do Sul (IFRS), Campus Ibirubá, Ibirubá, RS, Brasil

https://orcid.org/0000-0001-9518-3417, rodrigo.gama@ibiruba.ifrs.edu.br
\end{abstract}

\section{Informações do Artigo}

Como citar este artigo

HENRICHSEN, Luana; GAMA, Rodrigo

Farias. Reflexões sobre os métodos de

validações de jogos virtuais no ensino $e$

aprendizagem da Matemática. REMAT:

Revista Eletrônica da Matemática, Bento

Gonçalves, RS, v. 6, n. 2, p. e2004, 30 ago.

2020. DOI:

https://doi.org/10.35819/remat2020v6i2id3909

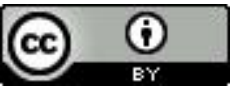

Histórico do Artigo

Submissão: 19 de fevereiro de 2020.

Aceite: 11 de junho de 2020.

Palavras-chave

Software Matemático

Jogos

Ferramenta Auxiliadora

Eficácia

Validações

\section{Resumo}

Este trabalho tem por objetivo realizar uma revisão bibliográfica sobre como são realizadas as validações dos jogos virtuais no processo de ensino e aprendizagem na disciplina de Matemática. Para isso, foi realizada uma pesquisa com as palavras-chave: jogos virtuais; Matemática; ensino, tanto em português quanto em inglês, por meio das plataformas Scopus, IEEE Xplore e Elsevier, buscando trabalhos compreendidos entre os anos de 2005 a 2019. Foram encontrados centenas de trabalhos e, após a leitura dos resumos, foram selecionados 20 deles. Entre esses trabalhos estavam artigos, dissertações, teses e livros que tratavam sobre jogos, tanto em esfera nacional, como internacional. Ao que compete aos selecionados, foram separados em três categorias: a) jogos tradicionais aplicados em qualquer disciplina; b) jogos tradicionais no ensino da Matemática; c) aplicação de jogos virtuais no ensino da Matemática. Nesta última categoria, foram selecionados quatro artigos para verificar quais as metodologias utilizadas para a validação dos dados obtidos a partir da aplicação dos jogos virtuais. Os resultados apontam que os dados, na maioria dos casos, são submetidos à estatística básica, como medidas de posição e frequência relativa. Além disso, apareceram dados analisados a partir do teste Shapiro Wilk, Usabilidade de Nielsen e Método do percurso cognitivo. Um dos artigos analisados não apresentou como foi desenvolvido o processo de validação dos dados. De modo geral, comprovou-se a eficácia dos jogos virtuais no ensino da Matemática.

\section{Keywords}

Mathematical Software

Games

Aided Tool

Efficiency

Validations

\section{Abstract}

This work aims to make a literature review about how the virtual games validations are realized in the teaching and learning process in Mathematics Subject. For this purpose, research was realized with the keywords: virtual games; Mathematics; teaching, in both Portuguese and English, through the platforms Scopus, IEEE Xplore and Elsevier, searching for papers published from 2005 to 2019. It was found in hundreds of works, and after reading the abstracts, only 20 were selected. Among these papers were articles, dissertations, theses, and books that deal with games, in national and international level. The selected papers were divided into three categories: a) traditional games applied in any subject; b) traditional games in Mathematics teaching; c) application of virtual games in Mathematics teaching. In this last category, four 
articles were selected to verify which methodologies were used to validate the data obtained from the virtual games application. The results indicated that, in most cases, the data are subjected to basic statistics, such as position's measures and relative frequency. In addition, data appeared from the Shapiro Wilk test, Nielsen Usability and Cognitive Path Method. One of the analyzed articles did not present how the data validation process was developed. In general, it proved the effectiveness of using virtual games in Mathematics teaching.

\section{Introdução}

Indo ao encontro do avanço da matemática, surgiram grandes nomes, os quais desenvolveram um papel de suma importância, como afirma Cury (2004, p. 7): "colocada em um mundo à parte, por Platão, louvada e admirada como modelo de ciência, por Descartes, apreciada como refúgio, por Russell, utilizada na elaboração de projetos que mudaram a face do mundo nos últimos séculos [...]".

A Matemática surge como parte da vida do homem, desde as noções primitivas de contagem, como afirma Boyer (1996, p. 1), pois, "parte da diferenciação de um lobo e muitos, da desigualdade de tamanho entre uma sardinha e uma baleia e a dessemelhança entre a forma redonda da lua e a retilínea de um pinheiro". Hoje, a Matemática compõe-se de métodos, ideias e procedimentos que são usados para raciocinar, avaliar e solucionar situações problemas. Além disso, busca pela razoabilidade de resultados, por regularidades, pela localização no tempo e no espaço, entre tantas outras formas de se interpretar suas funções.

Porém, não se pode afirmar que a Matemática é apenas a ciência dos números, como geralmente se é apresentada nas escolas, pois possui amplos campos, que na sua pluralidade e particularidade, constituem uma área de conhecimento, que alcança um extenso campo de linguagens, conceitos, formas de pensar e práticas, que estão sempre em constantes mudanças.

A Matemática, quando analisada como disciplina nas escolas, é vista pela maioria dos alunos como uma disciplina difícil, e o nível de rejeição é elevado. Muitos alunos afirmam que irão buscar por profissões que não envolverão raciocínio matemático. Esse bloqueio pela Matemática pode ser inconsciente, que procede de uma ideia pré-concebida. Segundo Sigmund Freud (1969, p. 17), "a pessoa sente prazer ou não naquilo que faz", logo, estudar Matemática e aprender a usá-la pode oferecer ou não prazer, gerando, portanto, esse bloqueio. Outro fator relacionado à rejeição está na motivação para aprender e no dar sentido e significado às coisas.

O papel do professor relaciona-se intimamente com essa motivação, pois cabe a ele adequar estratégias, materiais e metodologias, estabelecer conexões matemáticas entre os novos conceitos e os que já foram estudados, relacionando a Matemática teórica e a Matemática prática.

Apoiado ao cenário supracitado, Groenwald e Timm (2008) estimulam o uso de jogos para o processo de ensino e aprendizagem da Matemática, com o objetivo de mudar a rotina, despertar o interesse e estimular o gosto pela disciplina, pois os jogos tem um caráter lúdico que desenvolve técnicas intelectuais e ajuda a formar relações sociais. É incontestável a crescente utilização da 
tecnologia no meio social e, na educação. Isso se deve ao fato de que os estudantes têm contato direto com a tecnologia desde cedo; e a escola, por sua vez, adequa-se a essa nova realidade. As metodologias também passaram a ganhar uma face digital, e os jogos tradicionais estão dando espaço para os virtuais.

Nesse contexto, verifica-se que a tecnologia vem modificando e aprimorando a prática de metodologias no cenário educacional. Porém, as pesquisas que relacionam o jogo virtual com o processo de ensinar e aprender ainda são pouco comprovadas e, quando são corroboradas, isso ocorre de maneira empírica trazendo pouca confiabilidade aos dados apresentados. Portanto, o objetivo deste trabalho é verificar como são realizadas as validações dos jogos virtuais no processo de ensino e aprendizagem na perspectiva de evidenciar a sua importância dos jogos como uma ferramenta auxiliar a ser utilizada na disciplina de Matemática.

Neste intuito, este estudo apresenta uma análise feita através da rede mundial de computadores, em busca de trabalhos de cunho acadêmico (Elsevier, IEEE Xplore e Scopus) relacionando o uso desses jogos virtuais e o processo de análise para a validação dos mesmos.

\section{Jogos e as perspectivas atuais como uma ferramenta auxiliadora em sala de aula}

\subsection{O jogo tradicional e sua aplicação na disciplina de Matemática}

Os jogos sempre foram considerados excelentes estratégias no processo de ensino e de aprendizagem. Huizinga (1990), em "HOMO LUDENS: O jogo como elemento da cultura", explica que o jogo é muito mais que uma metodologia para contribuir nesse processo. Destaca que o jogo é uma realidade originária, que vem de relações primitivas afirmando que ele nasce da cultura.

A obra traz o jogo como um fenômeno cultural e não biológico, estudado em uma perspectiva histórica e não científica. Ou seja, integra o conceito de jogo no de cultura. Como diz:

Como a realidade do jogo ultrapassa a esfera da vida humana, é impossível que tenha seu fundamento em qualquer elemento racional, pois nesse caso, limitar-seia à humanidade. A existência do jogo não está ligada a qualquer grau determinado de civilização, ou a qualquer concepção do universo. Todo ser pensante é capaz de entender à primeira vista que o jogo possui uma realidade autônoma, mesmo que sua língua não possua um termo geral capaz de defini-lo. A existência do jogo é inegável. É possível negar, se quiser, quase todas as abstrações: a justiça, a beleza, a verdade, o bem, Deus. É possível negar-se a seriedade, mas não o jogo (HUIZINGA, 1990, p. 6).

Diante dessa introdução, ao discorrer, o autor reúne e busca inquietantemente interpretar o elemento mais misterioso da cultura humana: o instinto de jogar, e finaliza:

Conforme dissemos desde o início, o jogo está fora desse domínio da moral, não é em si mesmo nem bom nem mau. Mas sempre que tivermos de decidir se qualquer ação a que somos levados por nossa vontade é um dever que nos é exigido ou é lícito como jogo, nossa consciência moral prontamente nos dará a resposta. Sempre que nossa decisão de agir depende da verdade ou da justiça, da compaixão ou da clemência, o problema deixa de ter sentido. Basta uma gota de piedade para colocar nossos atos acima das distinções intelectuais. Em toda 
consciência moral baseada no reconhecimento da justiça e da graça, o dilema do jogo e da seriedade, até aqui insolúvel, deixará de poder ser formulado (HUIZINGA, 1990, p. 152).

Huizinga desperta que as realizações nas ciências, poesia, guerra, filosofia, lei e artes estão totalmente envolvidas pelo instinto de jogar, mostrando assim que "o jogar" vai muito além do que se imagina.

D’Ambrosio (1990), preocupado em estabelecer objetivos para o ensino de Matemática, buscou discutir sobre os aspectos relacionados à universidade e à intensidade; discorreu sobre as seguintes características: a Matemática pode ser útil como instrumentador para a vida; como instrumentador para o trabalho; faz parte integrante das raízes culturais; ajuda a pensar com clareza e a raciocinar melhor; por sua própria universidade e por sua beleza intrínseca como construção lógica.

Todas essas questões citadas pelo autor, em sua íntegra, apresentam aspectos relacionados ao elemento jogo. Essa importância do jogo está intimamente relacionada aos processos: situações de conflito, competições, resgate sociocultural, desenvolvimento de raciocínio, conhecimento da história do homem através de suas atividades lúdicas e o momento de prazer e descontração dos alunos. Esses processos procuram propiciar uma ampla significação ao ensino e aprendizagem da Matemática em seus diferentes níveis de ensino.

Segundo Yuste e Sallán (1988, p. 15), para se utilizar jogos no ensino de Matemática, é necessário que se crie um objetivo: introduzir os alunos nos procedimentos utilizados em Matemática na medida em que a forma do jogo, suas regras e tomadas de decisões, em cada movimento, são equivalentes aos elementos, definições e procedimentos de raciocínio necessários ao pensamento matemático.

Ainda segundo os autores, ocorrendo esse dinamismo, essa estrutura do jogo se assemelha às determinadas pela construção matemática. Pois, conseguindo vivenciar através do jogo, o aluno consegue compreender com mais facilidade a Matemática e seus processos.

Além disso, é necessário que se faça a escolha de uma metodologia de trabalho que permita a exploração do potencial dos jogos, e que eles sejam trabalhados com o intuito de fazer o aluno ir além da tentativa e erro, ou seja, além do jogar por jogar. Dentro dessa perspectiva, inúmeros pesquisadores estão em busca de respostas sobre os efeitos dos jogos na vida acadêmica dos alunos.

Barros e Angelim (2017) fazem uma revisão bibliográfica sobre os jogos aplicados na disciplina de Matemática com foco nos benefícios sob a motivação e o despertar do discente pela Matemática. Nesse sentido, os autores afirmam:

É nesse sentido, que os docentes da educação matemática e outras ciências que se utiliza do jogo educativo, busca engrandecer e motivar o aprendizado, desenvolver a autoconfiança, organização, concentração, atenção, raciocínio lógico-dedutivo e senso cooperativo, aumentando a socialização, promovendo o interesse e a partilha de ideias entre discente/docente (BARROS; ANGELIM, 2017, p. 2). 
Os mesmos autores enfatizam a perspectiva de engrandecer o ensino, ressaltando que o jogo tem uma boa aplicabilidade e que pode ser utilizado como parâmetro inicial em qualquer disciplina, mas, destacam que o docente não pode se apoiar apenas na utilização dos jogos.

Mota (2009) realizou a pesquisa "Jogos no ensino da matemática", que verificava os estudos teóricos e práticos da utilização de jogos no processo de ensino e de aprendizagem da disciplina de Matemática e concluiu que a maioria dos professores consideram que os jogos facilitam a transmissão de conhecimento e conceitos, motivando os alunos para, consequentemente, obterem sucesso na disciplina de Matemática.

Logo, jogos, atividades para exercitar a habilidade de pensar de forma mais cautelosa, e até mesmo as brincadeiras conseguem ensinar com maior eficiência, pois transmitem informações que, consequentemente, estimulam diversos sentidos, fazendo com que os apelos sensoriais possam ser multiplicados e isso faz com que a atenção e o interesse do aluno sejam mantidos. Dinello (2004, p. 1) explica que as crianças, ao jogar ou desenvolver atividades lúdicas, manifestam uma aprendizagem de habilidades, transformando sua agressividade em outras relações criativas, crescendo em imaginação, e também socializam e melhoram seu vocabulário.

\subsection{Jogos virtuais: uma ferramenta auxiliadora em sala de aula}

Desde o momento em que o computador e a internet passaram a fazer parte da vida das pessoas, houve grandes evoluções para o cotidiano das bilhões de pessoas no mundo, deixandoas conectadas e com acesso às informações de todos os lugares do planeta a qualquer instante. Isso trouxe comodidade e praticidade a todos. Junto com essa nova era, o antigo jogo tradicional dá abertura para os jogos virtuais. Os jogos eletrônicos surgem por volta dos anos 50 e sua popularidade vem se multiplicando ano após ano, atraindo as mais diversas faixas etárias da população.

Ao que se refere ao campo da educação, permite-se visualizar uma grande discussão em torno do uso dos jogos virtuais nas fronteiras entre educação, comunicação social e literatura. Segundo Aranha (2004, p. 1), em torno da educação, os jogos apresentam-se como uma promessa de aproximação dos sistemas de ensino em relação ao paradigma informacional. Em relação à comunicação social, novos processos de mediação digital e, ao que cabe à literatura, uma enigmática forma textual. Logo, busca-se um novo tipo de olhar a partir do uso da tecnologia dos jogos virtuais.

Essa promessa na educação ocorre, diretamente, dentro das escolas, com o uso dos recursos tecnológicos. Seus usos interferem, diretamente, nos processos educacionais, podendo ser utilizados como propostas criativas e como um ponto positivo na comunicação com os alunos, pois se permite trabalhar qualquer conteúdo de forma prazerosa e divertida. 
Segundo Falkembach (2007, p. 1), os jogos virtuais podem estimular a construção da autoconfiança e motivar os alunos no contexto da aprendizagem, além de que o próprio ato de jogar possibilita a expressividade de emoções e sentimentos.

Para além disso, os jogos virtuais podem ajudar o aluno a desenvolver habilidades e competências, como a persistência, no momento em que os vários desafios do jogo aparecem, aumenta a rede de conexões entre os neurônios, ou seja, melhora a flexibilidade intelectual.

Além disso, o jogo é capaz de melhorar a aprendizagem do conteúdo que está sendo trabalhado, abrindo a possibilidade de um maior entendimento, bem como permitir a melhor tomada de decisão e aperfeiçoar sua estratégia de jogo, o que, consequentemente, o ajudará a tomar decisões bem pensadas em situações reais. Outra vantagem é a significação de conceitos de difícil compreensão. Além disso, o jogo requer participação ativa no jogo, fazendo com que haja interação com os demais jogadores e estimule o trabalho em equipe. Por conseguinte, estimula a competição sadia e o prazer em aprender.

Prensky (2010), em "Não me atrapalhe mãe - Eu estou aprendendo", afirma que quando usados de maneira apropriada, os videogames podem ser extremamente importantes na vida das crianças:

Infelizmente, a maior parte das coisas que você ouviu sobre os games está completamente errada, ou, na melhor das hipóteses, bem longe da verdade. Os games não são os inimigos. As crianças de hoje querem ser envolvidas, e os games não só as envolvem, mas também ensinam lições valiosas durante o processo - lições que nós queremos que elas aprendam. Esses jogos, na verdade, são um meio importante pelo qual nossos filhos estão aprendendo, preparando-se para a vida no século XXI (PRENSKY, 2010, p. 28).

O autor ainda relaciona a atração ao fato de estarem aprendendo importantes estratégias para suas vidas e, afirma:

Os games modernos são formidáveis em fornecer às crianças novas perspectivas oportunidades desse tipo de aprendizado a cada segundo, ou mesmo frações de segundo. $E$ apesar de que a imprensa frequentemente poderia fazê-lo crer, a esmagadora maioria desse aprendizado é positiva (PRENSKY, 2010, p. 29).

Indo ao encontro da utilização de jogos virtuais no ensino de matemática, o mediador desse processo, o professor, tem um papel fundamental para que se atinjam os objetivos para com o jogo.

O professor é responsável por estudar, pesquisar e selecionar os jogos mais condizentes e apropriados com cada conteúdo que está sendo trabalhado, processo este que vai muito além de coletar informações. É indispensável que elabore e confronte visões, metodologias e que se trace objetivos para com os jogos.

Nessa esfera, o jogo, quando bem escolhido, deve difundir algumas peculiaridades: ser fácil de usar, agradável e principalmente, ser atrativo. Essa escolha não é difícil, mas mesmo depois de aplicado, requer uma cuidadosa avaliação do professor em relação ao jogo, como, por exemplo: O aluno conseguiu jogar sem dificuldades? Conseguiu entender o funcionamento do jogo, bem como os comandos, as opções de navegação? Logo, o professor terá de avaliar se o 
jogo foi eficiente para atingir seus objetivos e criar um bom instrumento para responder às suas inquietações. Mas qual instrumento utilizar? Como ter certeza se o instrumento comprovou, de forma satisfatória, se os jogos foram eficientes?

Com essas indagações, surge um ponto muito discutido entre pesquisadores dessa área: a problemática da validação dos jogos virtuais, sobre as quais irá ser discorrido na próxima subseção.

\subsection{A problemática da validação dos jogos virtuais}

Se procurarmos nas plataformas de pesquisa artigos relacionados a jogos, encontraremos uma infinidade de trabalhos. Isso se deve ao fato de o jogo ser objeto de inúmeras pesquisas. Kebritchi, Hirumi e Bai (2010, p. 2) afirmam que, embora se tenha incontáveis pesquisas, as falhas metodológicas nos estudos são um fator que impede fazer conclusões sólidas sobre os efeitos de jogos virtuais.

Os autores levantam uma importante questão: muitas pesquisas são consideradas empíricas, mas não trazem uma metodologia adequada para comprovar sua eficácia, conforme dizem:

O problema é que existe uma escassez de pesquisa empírica sobre o efeito dos jogos na aprendizagem em ambientes escolares [...] para orientar futuras pesquisas e práticas. Uma revisão de literatura superficial, usando a estrutura de Cooper (1985), indicou que dos 40 estudos revisados relacionados a jogos instrucionais, apenas 16 estudos empíricos e 4 revisões de literatura focaram no uso de jogos instrucionais para facilitar a aprendizagem em um ambiente escolar formal. As falhas metodológicas nos estudos empíricos são outro fator que nos impede de tirar conclusões sólidas sobre os efeitos dos jogos instrucionais na aprendizagem dos alunos (KEBRITCHI; HIRUMI; BAI, 2010, p. 3).

Kebritchi, Hirumi e Bai (2010, p. 3), ainda afirmam que o erro está intimamente ligado à falha no momento de montar a metodologia: "Um dos problemas frequentes é a falta de grupos de controle nos estudos. Examinar o efeito de um tratamento sem comparação com um grupo de controle é problemático".

Logo, é possível verificar falhas graves desde o início de uma pesquisa e, assim, torna-se difícil comprovar a eficácia dos jogos.

As visões contraditórias da revisão da literatura, a existência de relativamente poucos estudos empíricos em ambientes escolares e as falhas metodológicas citadas nos estudos empíricos exigem estudos empíricos mais rigorosos para ajudar os educadores a entender, implementar e facilitar os jogos em sala de aula (KEBRITCHI; HIRUMI; BAI, 2010, p. 3).

Com base nesses anseios e observações é que surge o grande objetivo deste trabalho. Como são realizadas as validações dos jogos virtuais no processo de ensino e aprendizagem na disciplina de Matemática? Para isso, foram selecionados quatro trabalhos, três de âmbito nacional e um internacional, os quais fizeram aplicações de jogos virtuais na disciplina de Matemática. 


\section{Metodologia}

Para atingir o objetivo do artigo, foi realizada uma pesquisa com as palavras-chave: jogos virtuais; Matemática; ensino, tanto em português quanto inglês, nas plataformas: Scopus, IEEE Xplore e Elsevier, buscando trabalhos compreendidos entre os anos de 2005 e 2019. Foram encontrados centenas de trabalhos; após a leitura dos resumos, foram selecionados apenas 20.

Entre esses trabalhos estavam artigos, dissertações, teses e livros que tratavam sobre jogos, tanto em esfera nacional como internacional. Ao que compete aos selecionados, foram separados em três categorias: a) jogos tradicionais; b) jogos tradicionais no ensino da Matemática; e c) aplicação de jogos virtuais no ensino da Matemática. Nesta última categoria, foram selecionados quatro artigos para verificar quais as metodologias utilizadas para a validação dos dados obtidos a partir da aplicação dos jogos virtuais. Os artigos analisados estão divididos na seção seguinte, em quatro subseções.

\section{Análise dos artigos selecionados para verificação de como são validados os resultados obtidos após aplicação de jogos virtuais}

\subsection{Análise do artigo: Jogos educativos em dispositivos móveis como auxílio ao ensino da Matemática}

O objetivo deste trabalho, segundo os autores, Barbosa Neto e Fonseca (2013), foi o de apresentar um estudo da utilização de jogos educativos digitais desenvolvidos para dispositivos móveis no auxílio do ensino da Matemática. A partir do objetivo, os autores, baseados em outros estudos, levantaram a hipótese de que os jogos digitais, enquanto ferramentas educacionais, poderiam ajudar para o desenvolvimento de conhecimento e habilidades cognitivas como a resolução de problemas, entre outros.

Barbosa Neto e Fonseca (2013) desenvolveram um jogo e aplicaram com dezesseis alunos. Destes, quatro eram oriundos de escola particular, do oitavo ano do Ensino Fundamental, e doze alunos de uma escola pública estadual do primeiro ano do Ensino Médio. O jogo passou pelo processo de desenvolvimento sugerido por outro estudo e processo, os quais, segundo os autores são: análise e planejamento, modelagem do jogo e implementação e testes com especialistas.

Este jogo foi baseado no livro "O homem que calculava" de Malba Tahan. Dentre as histórias que nele se encontram, foi escolhida a dos 35 camelos e os irmãos que brigavam por essa herança. Na história, surge Beremiz, personagem principal do livro, que cede o seu camelo para que os irmãos consigam fazer a partilha da herança conforme o testamento.

A primeira parte do jogo conta essa história e, nas próximas etapas, caberá ao jogador fazer a divisão dos camelos e resolver o problema da herança. No momento em que concluía, aparece se a divisão feita estava correta ou não. Na sequência, aparecia outra etapa, em que o 
jogador deveria selecionar os conceitos matemáticos aprendidos em sala de aula utilizados para a resolução do problema anterior.

Para a avaliação dos resultados, os pesquisadores seguiram critérios baseando-se em outros autores, buscaram usar instrumentos avaliativos de softwares educacionais e escolheram o questionário de avaliação para verificar o impacto do jogo no processo de ensino aprendizagem de Matemática. Logo, foram aplicados questionários individualizados e, para a análise dos dados, foi utilizado o método de frequência relativa em todas as questões.

Como resultados, os autores destacam que:

Os resultados obtidos pela aplicação dos questionários apontam que a maioria dos participantes respondeu de forma positiva sobre a usabilidade do jogo. Pois, $100 \%$ dos participantes concordaram que o jogo reconheceu corretamente seus movimentos (toques), enquanto outros $88 \%$ concordaram com a afirmativa: "entendi rapidamente o que deveria fazer para interagir com o jogo", apontou a satisfação ao interagir com a aplicação (BARBOSA NETO; FONSECA, 2013, p. 8).

Ainda segundo estudiosos, após um mês da realização do experimento com os alunos, foi apresentado um questionário para os professores de Matemática dos alunos envolvidos neste estudo. A maioria dos alunos estavam mais motivados com o processo de ensino e aprendizagem e mais participativos em aula.

Nesse trabalho, foi possível verificar como foram realizadas as validações do jogo em questão, pois os autores optaram por questionários de avaliação para coletar os dados referentes ao jogo e, para a interpretação dos dados, fizeram uso da estatística básica, mais especificamente distribuição de frequência relativa. Vale ressaltar que a frequência relativa é o resultado obtido pela divisão entre a frequência absoluta (o valor observado na pesquisa) e a quantidade de amostras (nesse caso, os alunos).

Barbosa Neto e Fonseca (2013) não abordam problemas na pesquisa e não citam a possibilidade de novas aplicações antes de levar o acesso do jogo a público. Destaca-se que os autores conseguiram sucesso na pesquisa, comprovando a eficácia e estão adaptando o jogo para diversos tipos de dispositivos móveis.

\subsection{Análise do artigo: Os jogos digitais são realmente melhores que os jogos tradicionais para ensinar Matemática? Uma análise sob a concentração dos estudantes}

O objetivo deste trabalho, conforme os autores Santos e Santana (2018) discorreram, foi o de comparar a versão tradicional de um jogo para o ensino de Matemática com sua versão digital.

Os pesquisadores optaram pelo jogo desafios com palitos, em que se utilizaram de uma versão tradicional e de uma digital do mesmo jogo. O estudo foi caracterizado como comparativo e quantitativo, foi conduzido com 34 alunos do Ensino Fundamental de uma escola particular do Brasil. 
Para atingir o objetivo, foi utilizado o método de divisão randômica igualitária, no qual divide-se uma turma em dois grupos distintos de maneira aleatória. Um grupo, denominado experimental, foi convidado a jogar a versão digital do jogo, enquanto o outro grupo, denominado controle, jogou a versão tradicional. A aplicação das duas versões se deu de modo simultânea, segundo Santos e Santana (2018), em que os grupos não tinham ciência do que se passava na outra sala. Os jogos ficaram disponíveis aos alunos por, aproximadamente, meia hora, e, após esse tempo, os estudantes responderam um questionário demográfico e outro de avaliação de concentração, este último foi elaborado através de outros estudos.

Ainda no que se refere à metodologia, os autores levantaram duas hipóteses para análise dos resultados, descreveram o que era cada elemento estatístico, como fator, níveis do fator e qual a variável resposta.

Ao que concerne os resultados, Santos e Santana (2018) compararam os dados das duas versões do jogo através do uso da estatística básica, mais precisamente utilizando medidas de posição, em que foi possível verificar que o jogo em sua versão tradicional teve maior êxito em termos de concentração.

Posteriormente, os dados foram submetidos ao teste Shapiro-Wilk e, após aplicação do teste, foi indicado que não houve diferença estatisticamente significante na concentração dos estudantes em ambas as versões.

Logo, Santos e Santana concluíram que:

Os resultados deste estudo indicam que a substituição de métodos e objetos tradicionais de ensino (como é o caso dos jogos tradicionais/analógicos) por novas tecnologias, independente do público, não garante uma melhora na construção de conhecimento dos estudantes. Os resultados nos apresentam indícios da possibilidade de utilização mista destas tecnologias, em outras, do uso do digital em parceria com o tradicional (SANTOS; SANTANA, 2018, p. 7).

Além disso, ressaltaram a importância de aplicar o estudo em outras circunstâncias para se ter mais dados para comparação. Evidenciaram, também, ameaças que podem ter influenciado na obtenção dos resultados como: história, maturação e viés positivo, ressaltando o cuidado que tiveram, embora soubessem dessas ameaças, bem como, o tamanho da amostra que foi muito pequena para uma análise estatística.

Corroborando o trabalho de Barbosa Neto e Fonseca (2013), os autores fizeram uso de estatística básica, utilizando-se de média, moda e mediana. Além disso, usaram o Teste de Shapiro-Wilk, que testa a hipótese nula em uma amostra retirada de uma população que tem distribuição normal.

Santos e Santana citam alguns problemas que possam ter influenciado nos dados, as chamadas ameaças, e destacam que a amostra foi pequena e o jogo precisa ser testado mais vezes em diversos ambientes. Mesmo assim, o jogo teve êxito. 


\subsection{Análise do artigo: Robô Euroi: jogo de estratégia matemática para exercitar o pensamento computacional}

Melo et al. (2018) apresentam o jogo Robô Euroi como uma proposta para a disciplina de Matemática com foco na associação de número e quantidade para crianças na fase de alfabetização. O seu objetivo é o de promover o desenvolvimento do pensamento computacional por meio da aprendizagem matemática.

De forma geral, os autores salientam algumas habilidades do jogo, através do pensamento computacional, tais como abstração e tomadas de decisões. Para dar suporte ao jogo, foi utilizada fundamentação teórica como a teoria da carga cognitiva e a teoria cognitiva da aprendizagem multimídia.

O jogo é caracterizado como mobile $2 \mathrm{D}$, com estilo retro e plataforma que trabalha com fundamentos matemáticos e procura desenvolver habilidades do pensamento computacional. Os autores discorreram a respeito do processo de desenvolvimento do jogo: ideação e planejamento; prototipagem; história do jogo; e mecânicas do jogo.

Robô Euroi é um jogo no qual o personagem principal, Euroi, é mandado para o espaço controlado por um grupo de cientistas da Terra, pois uma nave de astronautas entrou em colisão com um meteorito e caiu em um planeta desconhecido. Euroi precisa passar por diversos planetas para recuperar as peças da nave, consertá-la e voltar em segurança com os astronautas, porém enfrenta diversos desafios. O personagem tem uma bateria de energia, e os planetas são energizados, tendo energias positivas e negativas, dependendo por onde passar, perde ou ganha energia. Além disso, tem inimigos que, em contato com Euroi, podem fazê-lo perder energias.

O objetivo do jogo é Euroi chegar ao fim sem que acabe a bateria e que consiga recuperar todas as peças da nave e com os astronautas em segurança.

Melo et. al. (2018), confirmam o êxito do jogo, apresentando as seguintes porcentagens:

O jogo Robô Euroi obteve as maiores porcentagens, entre bom e perfeito, nos seguintes critérios: $71 \%$ usabilidades de Nielsen, $81 \%$ TCAM, $76 \%$ concentração, $97 \%$ desafio, $96 \%$ habilidades do jogador, $81 \%$ controle, $100 \%$ objetivo e $82 \%$ feedback. Os resultados foram bastante importantes para que fossem realizados ajustes no jogo (MELO et al., 2018, p. 8).

Os autores ainda destacam que, com esses resultados, o protótipo testado foi aprovado e, através do GameFlow, o jogo entrou na classificação de Gamificação.

Melo et. al. (2018) usaram processos metodológicos e outros testes para a validação do jogo. Dentre os testes, o teste de usabilidade de Nielsen, que nada mais é que uma técnica de pesquisa utilizada para avaliar um produto ou serviço, nesse trabalho, o próprio jogo. Já o método do percurso cognitivo é um método de avaliação por inspeção, cujo principal objetivo é avaliar a facilidade de aprendizado de um sistema interativo através da exploração da sua interface. Quanto ao Gameflow, trata-se de uma ferramenta visual de script e automação para quebrar o 
molde projetado para ser fácil de usar e imediatamente útil para os projetos, ou, neste caso, para o jogo.

\subsection{Análise do artigo: Teaching spatial geometry in a virtual world: using Minecraft in Mathematics in grade 5/6 (Ensinando geometria espacial em um mundo virtual: usando Minecraft em Matemática no $5^{\circ} / 6^{\circ}$ ano)}

Foerster (2017, p. 2) fez uso do Minecraft para ampliar o ensino de geometria espacial nos $5^{\circ}$ e $6^{\circ}$ anos do Ensino Fundamental. O jogo é do tipo sandbox (colaborativo) no qual blocos do tipo lego podem ser colocados e removidos. Há o modo de construção bem como o modo de sobrevivência. Os jogadores começam com um inventário vazio e precisam reunir todos os recursos desejados, enquanto o mundo é preenchido com um não jogador amigável.

A avaliação do jogo foi dividida em dois estudos, sendo 103 alunos participantes divididos em três grupos, 69 no $5^{\circ}$ ano, 12 no $6^{\circ}$ ano e mais um grupo controle de 22 alunos. O primeiro estudo era focado na transferência entre o plano, o espaço e o edifício colaborativo. O segundo focado em implementar a sugestão de escala de Bos.

No que se refere ao primeiro estudo, os alunos deveriam transferir seus objetos desenhados do avião para o espaço do mundo virtual e ver se teriam problemas com a orientação espacial.

No segundo estudo, o intuito era dimensionar construções do Minecraft e seu impacto de curto prazo nas habilidades espaciais. Os alunos esboçaram uma construção desejada e depois construíram duas vezes, uma em tamanho normal e outra em dimensões de tamanho duplicada. O grupo controle recebia um questionário para comparar os dois grupos.

Foerster afirma que, no primeiro estudo, todos os alunos, com exceção de um, não tiveram problemas em se orientar no mundo virtual do Minecraft. No segundo estudo, os alunos esboçaram uma construção, depois construíram em tamanho normal em 10 minutos e depois tentaram construí-la em escala dupla em 20 minutos. Apenas um aluno conseguiu concluir completamente sua construção.

De modo geral, o autor acredita que o Minecraft seja uma ferramenta adicional útil para o ensino de geometria espacial no $5^{\circ}$ e $6^{\circ}$ anos.

O trabalho do autor, de forma geral é bom, a ideia de usar um jogo tão famoso no mundo virtual é muito interessante. Porém não especifica como validou o jogo, como analisou e interpretou seus dados, o que torna a pesquisa questionável.

\section{Considerações finais}

Como podemos verificar, os jogos virtuais para ensino e aprendizagem na disciplina de Matemática podem ser uma excelente ferramenta auxiliadora, desde que se tenha um planejamento do que será abordado por trás de um jogo e, principalmente, como vimos nas 
colocações de diferentes autores, que se tenha uma organização para aplicar os jogos e um objetivo a ser alcançado, para não se tornar apenas um jogar por jogar.

Alcançamos nosso objetivo que era o de verificar como são realizadas as validações dos jogos virtuais na Matemática. De modo geral, verificamos que os trabalhos são validados através de estatística básica, como média, moda, mediana e frequência relativa. Outros testes apareceram, como Shapiro Wilk, teste de usabilidade de Nielsen e o método de percurso cognitivo.

Em trabalhos futuros, buscaremos continuar a verificação da validação dos jogos e entender por que os métodos de validação e interpretação dos dados são pouco ressaltados nos trabalhos científicos.

\section{Referências}

ARANHA, G. O processo de consolidação dos jogos eletrônicos como instrumento de comunicação e de construção de conhecimento. Ciências \& Cognição, Rio de Janeiro, v. 3, ano 1, p. 21-62, nov. 2004. Disponível em:

http://www.cienciasecognicao.org/revista/index.php/cec/article/view/473. Acesso em: 16 mar. 2019.

BARBOSA NETO, J. F.; FONSECA, F. S. da. Jogos educativos em dispositivos móveis como auxílio ao ensino da matemática. RENOTE: Revista Novas Tecnologias na Educação, Porto Alegre, v. 11, n. 1, jul. 2013. DOI: https://doi.org/10.22456/1679-1916.41623.

BARROS, M. L. L.; ANGELIM, C. P. O Uso dos Jogos no Ensino da Matemática. Id on Line: Revista Multidisciplinar e de Psicologia, Jaboatão dos Guararapes, v. 11, n. 39, p. 452-458, 2017. DOI: https://doi.org/10.14295/idonline.v12i39.1004.

BOYER, C. B. História da Matemática. 2 ed. São Paulo: Edgard Blücher, 1996.

CURY, H. N. Disciplinas Matemáticas em Cursos Superiores: reflexões, relatos, propostas. Porto Alegre: EDIPUCRS, 2004.

D'AMBROSIO, U. Etnomatemática: arte ou técnica de explicar e conhecer. São Paulo: Ática, 1990.

DINELLO, R. Os jogos e as ludotecas. Santa Maria: Pallotti, 2004.

FALKEMBACH, G. M. O lúdico e os jogos educacionais. 2007. Universidade Federal do Rio Grande do Sul. Disponível em:

http://penta3.ufrgs.br/midiasedu/modulo13/etapa1/leituras/arquivos/Leitura 1.pdf. Acesso em: 16 mar. 2019.

FOERSTER, K. T. Teaching spatial geometry in a virtual world: Using minecraft in mathematics in grade 5/6. 2017 IEEE Global Engineering Education Conference (EDUCON), Athens, p. 14111418, june 2017. DOI: https://doi.org/10.1109/EDUCON.2017.7943032.

FREUD, Sigmund. Obras Completas. Rio de Janeiro: Imago, 1969.

GROENWALD, C. L. O.; TIMM, U. T. Utilizando Curiosidades e Jogos Matemáticos em Sala de Aula. Só Pedagogia, Virtuous Tecnologia da Informação, 9 jul. 2008. Disponível em:

http://www.pedagogia.com.br/artigos/jogoscuriosidades/. Acesso em: 10 ago. 2020. 
HUIZINGA, J. Homo Ludens: o jogo como elemento da cultura. 2 ed. Trad.: MONTEIRO, João Paulo. São Paulo: Perspectiva, 1990.

KEBRITCHI, M.; HIRUMI, A.; BAI, H. The effects of modern mathematics computer games on mathematics achievement and class motivation. Computers \& Education, v. 55, n. 2, p. 427-443, set. 2010. DOI: https://doi.org/10.1016/j.compedu.2010.02.007.

MELO, D. S. de; PIRES, F. G. S; FERREIRA, R. M; SILVA JÚNIOR, R. J. R. Robô Euroi: jogo de estratégia Matemática para exercitar o Pensamento Computacional. Brazilian Symposium on Computers in Education (Simpósio Brasileiro de Informática na Educação - SBIE), p. 685, out. 2018. DOI: http://dx.doi.org/10.5753/cbie.sbie.2018.685.

MOTA, P. C. C. L. de M. Jogos no Ensino da Matemática. 2009. 142 f. Dissertação (Mestrado em Matemática/Educação) - Universidade Portucalense, Porto, Portugal, 2009.

PRENSKY, M. Não me atrapalhe mãe - estou estudando. São Paulo: Phorte, 2010.

SANTOS, W. O. dos; SANTANA, S. J. de. Os Jogos Digitais São Realmente Melhores que os Jogos Tradicionais para Ensinar Matemática? Uma Análise sob a Concentração dos Estudantes. RENOTE: Revista Novas Tecnologias na Educação, Porto Alegre, v. 16, n. 1, jul. 2018. DOI: https://doi.org/10.22456/1679-1916.85906.

YUSTE, F. C; SALLÁN, J. M. Juegos en clase de matematicas. Cuadernos de Pedagogia, n. 160, p. 50-51, 1988. Disponível em: https://dialnet.unirioja.es/servlet/articulo?codigo=2769007. Acesso em: 10 ago. 2020. 